\section{Roentgenographic assessment of Achilles tendon rupture}

We read with interest the article by Michael and Banerjee' entitled 'Apparent tendo Achilles rupture in the elderly: is routine radiography necessary? The authors 'stressed the need for radiographic assessment of suspected tendo Achilles ruptures in the elderly' and in the following discussion they mentioned that it is not routine practice to obtain radiographs when tendo Achilles ruptures is diagnosed' suggesting that radiographic analysis should form part of the 'routine assessment of suspected tendo achilles ruptures in this age group'.

These statements seem to ignore the fact that radiology can be a useful aid in diagnosis of Achilles tendon rupture in young people. A correct diagnosis of Achilles tendon rupture is of the utmost importance because overlooked rupture can often lead to an appreciable loss of function, whereas adequate treatment generally results in good functional conditions. It has been emphasized that as many as $25 \%$ of patients with a total rupture of the Achilles tendon were primarily misdiagnosed in the accident and emergency department. ${ }^{2-4}$ Roentgenographic examination is simple and inexpensive and could be a valuable supplement in the diagnosis of ruptured Achilles tendon in all age groups.

There are many roentenographic signs of acute rupture of Achilles tendon. Kager's triangle is a space filled with fatty tissue, bordered by margins of the anterior surface of the Achilles tendon, the upper part of the calcaneus, and the posterior surface of the deep flexor tendons. ${ }^{5}$ When the Achilles tendon is ruptured, the sharp contour of the fat pad in Kager's triangle will disappear. The margins become serrated and indistinct. Also the triangle will become smaller, less transparent, and covered by a network-like shadow. The abnormal roentgenographic features are defined as positive Kager's sign (Figs $1 \& 2$ ). Toygar's angle is the angle of the posterior skin surface curve visualized on the roentgen film. ${ }^{6}$ This angle should diminish in patients with Achilles tendon rupture and is considered pathological if less than $150^{\circ} .^{7}$ Positive Arner's sign-the pathological roentgenographic configuration for rupture of the Achilles tendon-illustrates that the anterior contour of the Achilles tendon curves away from the calcaneus between the insertion of the Achilles tendon at the posterior area of the calcaneus and the upper part of the calcaneus. ${ }^{7}$ The thickness of the Achilles tendon can also be measured, and a thickness of more than $8 \mathrm{~mm}$ with the focus-film distance of $100 \mathrm{~cm}$, should be considered abnormal.

Cetti and Andersen ${ }^{8}$ have recently investigated the roentgenographic features of the Achilles tendon in

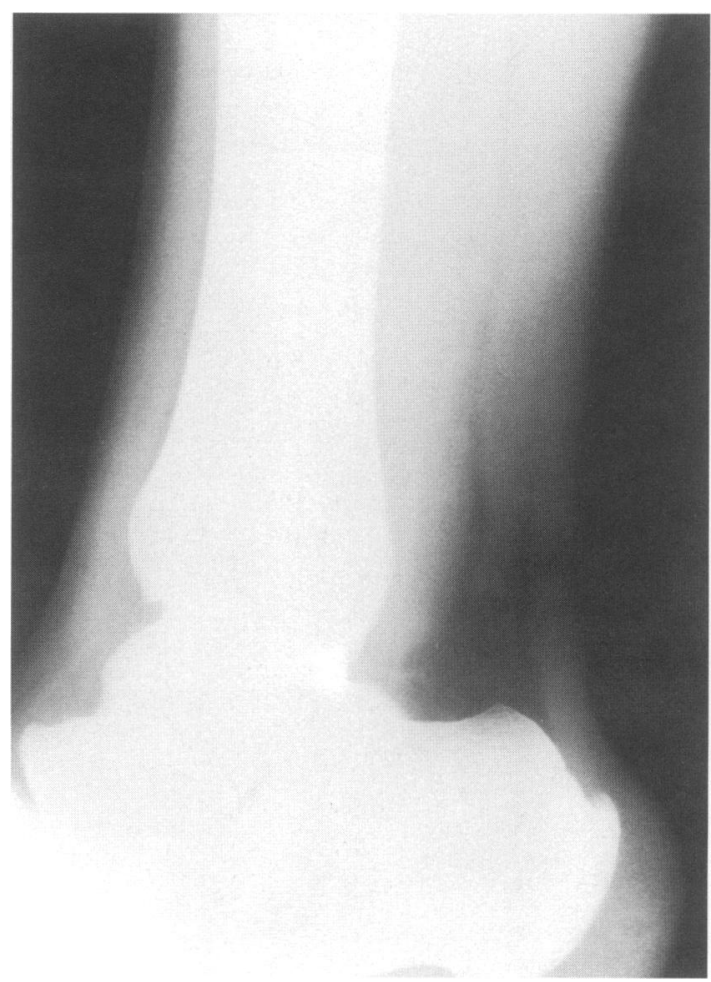

Fig. 1. Lateral roentgenograph of the ankle showing a normal Achilles tendon. Kager's triangle is clearly perceptible with smooth margins. 


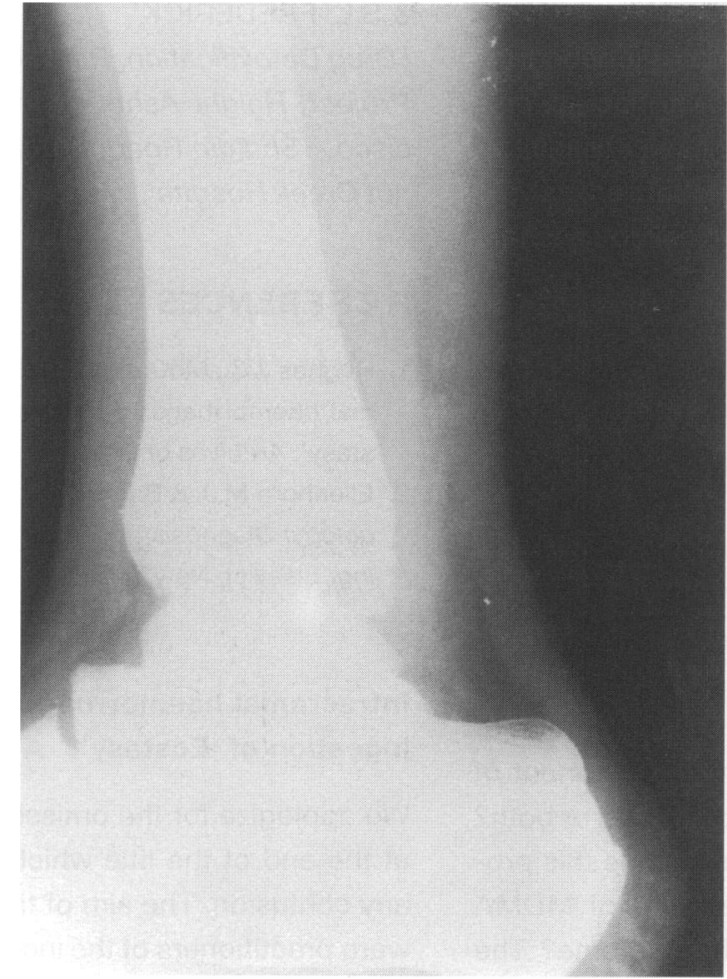

Fig. 2. Lateral ankle roentgenopraph in a patient suffering from a rupture of the Achiles tendon. Kager's triangle is small, less transparent, and covered by a network-like shadow. Toygar's angle has decreased and is less than $150^{\circ}$.

patients with acute total rupture, comparing with a reference groups of ankle fractures, ankle sprains and ankles without actual trauma. Kager's triangle was positive for rupture of the Achilles tendon in all patients, $12 \%$ had diminished Toygar's angle, $48 \%$ had positive Arner's sign, and $78 \%$ of patients with ruptured Achilles tendon had a thickness of the tendon compared with the opposite Achilles tendon. To lower the frequency of overlooked Achilles tendon rupture, any doubt as to whether a ruptured Achilles tendon is present should result in a lateral soft tissue roentgenographic examination of the ankle in all age groups. However, many radiographs of the ankle are taken to enable exclusion of fracture, and this does not always lead the physician to a correct diagnosis. The roentgenographic investigation should concentrate on Kager's triangle, which is easily identified and present a good specificity and a fine sensitivity for rupture of the Achilles tendon ${ }^{8}$.
A. COMBALIA' \& J. NARDI ${ }^{2}$

'Department of Orthopaedics and Trauma, Hospital Clinic, University of Barcelona, ${ }^{2}$ Department of Orthopaedics and Trauma, Hospital Valle Hebrón, Autonomous University of Barcelona, Barcelona, Catalonia, Spain

\section{REFERENCES}

1. Michael S. \& Banerjee A. (1993) Apparent tendo Achilles rupture in the elderly: is routine radiography necessary? Archives of Emergency Medicine 10, 336-338.

2. Akermark C. (1992) Difficulty in diagnosing total rupture of the Achilles tendon. Every fifth case is missed by the physicians involved in the initial treatment. Lakartidningen 89, 3681-3683.

3. Combalia A. (1994) Estudio estructural, ultraestructural y clínico de la rotura del tendon de Aquiles en el deportista. Tesis Universidad de Barcelona.

4. Józsa L., Kvist M., Balint B.J., Jarvinen M., Lehto M. \& Barzo M. (1989) The role of recreational sport activity in Achilles tendon rupture. A clinical, pathoanatomical, and sociological study of 292 cases. American Journal of Sports Medicine 17, 338-343.

5. Kager H. (1939) Zur klinik und diagnostik des achillessehnenrisses. Chirurg (Berlin) 11, 691-695.

6. Toygar V.O. (1947) Subkutane ruptur der achillessehne, diagnostik und behandlungsergebnisse. Helvetica Chirurgica Acta 3, 209-231.

7. Arner O., Lindholm A. \& Lindvall N. (1958/59) Roentgen changes in subcutaneous rupture of the Achilles tendon. Acta Chirurgica Scandinavica 116, 496-500.

8. Cetti R. \& Andersen I. (1993) Roentgenographic diagnoses of ruptured achilles tendons. Clinical Orthopaedics 286, 215-221.

\section{Amphetamine, not MDMA, is associated with intracranial hemorrhage}

A case report entitled 'Intracranial haemorrhage associated with ingestion of "Ecstasy"' is fraught with errors. ' Chief among these errors are the misleading title and summary, as no 'Ecstasy' was involved. The authors define 'Ecstasy' as ' $3-4$ methylene-dioxymethamphetamine (MDMA)', but go on to state that drug analysis revealed the presence of amphetamine, not MDMA. Consideration of MDMA as a possible aetiological agent was purely anecdotal, being derived from history given by a friend to the effect that the patient had 'apparently taken "Ecstasy"'. No information is presented from this friend as to the basis of her 